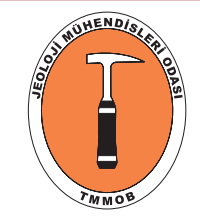

\author{
Türkiye Jeoloji Bülteni \\ Geological Bulletin of Turkey \\ $63(2020) 69-82$ \\ doi: $10.25288 /$ tjb. 571382
}

\title{
Kentsel Faaliyetlerin Kıyı Akiferlerine Etkileri: Doğu Karadeniz Havzası Örneği
}

Effects of Urban Activities on Coastal Aquifers: Case Study in the Eastern Black Sea Basin

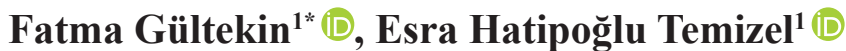

${ }^{1}$ Karadeniz Teknik Üniversitesi, Jeoloji Mühendisliği Bölümü, 61080, Trabzon

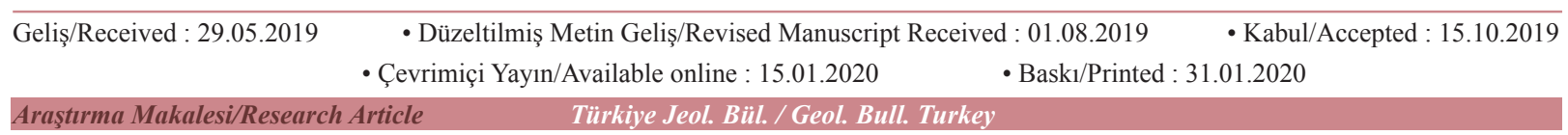

Öz: Ortalama yağış yüksekliği 1300 mm olan Doğu Karadeniz Havzası ülkemizin en fazla yağış alan bölgesidir. Ancak bu bölge, topoğrafyasının aşırı derecede eğimli, havzada yüzeylenen kayaçların geçirimsiz-az geçirimli olmasına bağlı olarak kaynak ve yeraltısuyu potansiyeli açısından ülkemizin en fakir bölgeleri arasında yer alır. Doğu Karadeniz kıyı şeridi boyunca kuzeyden güneye doğru derin vadiler oluşturarak akan akarsuların taşıdığı alüvyonlar denize yakın kısımlarda yeraltısuyu bakımından önem taşımaktadır. Kalınlıkları ve genişlikleri kuzeyden güneye gidildikçe azalan alüvyonların uzunlukları $1 \mathrm{~km}$ ile $16 \mathrm{~km}$ ve genişlikleri ise $50 \mathrm{~m}$ ile $1500 \mathrm{~m}$ arasında değişmektedir. Kalınlıkları en fazla $60 \mathrm{~m}$ olan bu alüvyonlarda açılmış olan kuyulardan içme-kullanma suyu sağlanmaktadır. DSİ (2015) verilerine göre statik su seviyesi $0,3 \mathrm{~m}$ ile $1 \mathrm{~m}$, dinamik su seviyesi $5 \mathrm{~m}$ ile $15 \mathrm{~m}$ arasında değişmektedir. Doğu Karadeniz Havzası kıyı akiferlerinde depolanan su hacmi 238 hm³'tür. Bu akiferlerin bir kısmı geçmişte bir kısmı ise halen içme-kullanma suyu kaynağı olarak kullanılmaktadır. Ancak dar vadiler arasındaki kısmen düz alanları oluşturan bu akiferler üzerinde son yıllarda sanayi siteleri, kum-mıcır gibi taş ocakları ürünleri, kömür depolama ve paketleme tesisleri, depolar ve bazı kamu kurum ve kuruluşlarının binaları gibi yapılaşmalar artmaktadır. $\mathrm{Bu}$ çalışmada bu yapıların akiferler üzerinde kapladığı alanlar tespit edilmiş ve akiferlerin tamamında yapılaşmanın olduğu, çoğunluğunda çeşitli depolama faaliyetlerinin, yarısında ise sanayi sitelerinin yer aldığı, bir kısmında da beton üretim faaliyetlerinin olduğu belirlenmiştir. Havzadaki akiferler havzanın en önemli yeraltısuyu kaynaklarıdır ve 4 ilin içme-kullanma suyunu karşılamak amacıyla kullanılmaktadır. Geçmişte içme-kullanma suyu sağlayan Değirmendere ve Taşlıdere akiferleri tamamen kentleşme baskısı altında kalmış ve yeraltısuyu kullanımı sonlanmıştır. Yerleşim yeri içerisinde kalan Melet, Civil, Pazarsuyu (Ordu) ve Batlama ve Keşap (Giresun) akiferlerinde kentsel faaliyetler artarak devam etmektedir. Havzada birçok kuyu yerleşim yeri içerisinde kalması sebebiyle, Giresun Pazarsuyu akiferinde ise mangan konsantrasyonun fazla olması nedeniyle kullanım dışı bırakılmıştır. Yeraltısuyu bulundurma kapasiteleri diğerlerine göre fazla olan Curi, Yağlıdere, İyidere ve Fırtına akiferleri kentleşmenin etkilerinin en az olduğu akiferlerdir. Daha uzun yıllar kullanılabilmesi için Doğu Karadeniz kıyı akiferlerinin kalite ve beslenme açısından korunması kaçınılmazdır.

Anahtar Kelimeler: Kıyı akiferleri, Doğu Karadeniz Havzası, kentsel faaliyetler.

\begin{abstract}
The Eastern Black Sea Basin is the highest rainfall area in Turkey with an average rainfall of 1300 $\mathrm{mm}$. However, this region is one of the poorest regions in terms of spring and groundwater potential due to its topography having extremely high slopes, and impermeable-less permeable rocks exposed in the basin. Alluvium, which is carried by streams flowing from north to south along the Eastern Black Sea coastline, are important in terms of groundwater. Alluvium, of which thickness and width decrease from north to south, has a length of 1-16 km and a width of 50-1500 m. Water is provided from wells that are drilled in alluvium with a thickness of up to $40 \mathrm{~m}$. According to DSI (2015) data, the static water level is between 0.3 and $1 \mathrm{~m}$, while the dynamic water level is between 5 and $15 \mathrm{~m}$. The volume of water stored in the coastal aquifers of the Eastern Black Sea Basin is $238 \mathrm{hm}^{3}$. Some of

*Yazışma / Correspondence: fatma@ktu.edu.tr

(C) 2020 JMO Her hakkl saklıdır/All rights reserved http://tjb.jmo.org.tr http://dergipark.gov.tr/tjb
\end{abstract}


these aquifers are still used and some were used in the past as drinking water sources. However, in recent years, construction such as industrial sites, quarries, coal storage and packaging facilities, warehouses and buildings of some public institutions and organizations has been increasing on these aquifers, which form partially flat areas between narrow valleys. This construction adversely affects both the quantity and quality of shallow groundwater stored in alluvium. The aquifers are the most important groundwater sources in the basin and are used to supply drinking and potable water for 4 cities. Değirmendere and Taşlldere aquifers, which provided drinking-potable water in the past, were completely under stress by urbanization and the use of groundwater was terminated. The urban activities on Melet, Civil, Pazarsuyu (Ordu) and Batlama and Keşap (Giresun) aquifers, which are located in the settlement area, continue to increase. The aquifers of Curi, Yağlıdere, Gelevera, Akhisar, Yanbolu, Baltacl, Iyidere and Firtına are less affected by urban activities. Among them, Curi, Yağlldere, İyidere and Firtına aquifers are aquifers with high groundwater capacities. In order to be able to use the Eastern Black Sea coastal aquifers for many years, it is necessary to protect them in terms of quality and recharging.

Keywords: Coastal aquifers, Eastern Black Sea Basin, urban activities.

\section{GİRIŞ}

Ülkemizde yerleşim birimlerinin su havzaları içerisinde dağınık bir şekilde bulunması en önemli sorunlardan biridir. Havzada bulunan yerleşim yerleri ve burada yaşayan nüfusun suyun miktarı ve kalitesi üzerinde pek çok olumsuz ve kalıcı etkileri vardır. Su kaynakları çevresinde bulunan yerleşim alanları ve buralardaki yapılaşma kaynakların etrafinda yeterli koruma bantları oluşturulmasına engel olmaktadır. Geçmişten günümüze kadar su kaynaklarının etrafinda ve su havzalarında iyi bir planlama yapılmadığı için artan nüfusun havzalardaki su kaynakları üzerinde oluşturduğu baskılar da artarak devam etmektedir (Yüksek, 2004). Kentsel alanların genişlemesi su kaynakları gibi doğal kaynaklar, hidrolojik dinamikler ve çevresel kalite üzerinde istenmeyen baskılar oluşturmuştur. Kentsel faaliyetler beslenme miktarını ve beslenme kanallarını değiştirerek, yeni drenaj kanalları oluşturarak yeraltı suyunun miktarını ve kalitesini etkilemektedir (Foster vd., 1998). Birçok büyük kentin su ihtiyacının yeraltısuları ile karşılandığının ve kentsel aktivitelerin bu akiferler üzerindeki etkilerinin incelendiği çok sayıda çalışma bulunmaktadır. Bunların çoğunluğunu yeraltısularının kalitesinin bozulması üzerine yapılan çalışmalar (Long ve Saleem, 1974; Fusillo vd., 1985; Nazari vd., 1993; Diaz-Fierros vd., 2002; Choi vd., 2005; McGrane vd., 2014) oluşturur. Yeraltısuyu seviyesinin değişmesi ile ilgili çalışmalar (Brassington ve Rushton, 1987; Knipe vd., 1993; Trivedi vd., 2001) ve kentsel alanların hidrolojik süreçlere etkilerinin incelendiği çalışmalar da (Niemczynowicz 1999; Vörösmarty vd., 2000; Naik vd., 2008; Hayashi vd., 2009; Fletcher vd., 2013; McGrane, 2016) giderek önem kazanmaktadır.

Kentlerde nüfusun artışı, su kaynakları üzerindeki baskıyı artırırken su gereksiniminin artmasını ve yeni su kaynaklarının aranmasını da gündeme getirmiştir. Doğu Karadeniz'deki şehir ve ilçe merkezlerinin tamamı 2000'li yıllara kadar içme-kullanma suyu gereksinimlerini etrafında yerleştikleri nehir veya dere alüvyonlarından karşılamıştır. İlçe merkezlerinin tamamına yakını halen yeraltı suyunu kullanmaktayken bazı şehir merkezleri ve ilçeler arıtılmış yüzey sularını kullanmaya başlamıştır. Rize'de Poşut, Çağırankaya ve Ilıca Derelerinden alınan su Andon İçme Suyu Arıtma Tesisi'nde arıtıldıktan sonra içme-kullanma suyu olarak kullanılmaktadır. Trabzon ilinin içme-kullanma suyu ilin $17 \mathrm{~km}$ güneyinde, Değirmendere'nin bir kolu olan Galyan Deresi üzerinde yer alan Atasu Barajı'ndan sağlanmaktadır. Giresun ili içme-kullanma suyunun tamamını, Ordu ili ise büyük bir kısmını yeraltısularından elde etmektedir (DSİ, 2015).

Ancak Doğu Karadeniz Havzası'nda halen birçok yerleşim yerine içme-kullanma suyu sağlayan alüvyon akiferler yerleşim alanları 
içerisindedir ve kentleşmenin etkisi altında kalmaktadır. Yerleşim yerlerinin tamamında genişlikleri en fazla bir kilometre uzunlukları birkaç kilometre olan bu alüvyon yüzeylenmeler üzerinde sanayi siteleri, çeşitli depolama işlemleri, ulaşım faaliyetleri, mıcır-kum gibi malzeme üretim alanları gibi yapılaşmalar giderek artmaktadır. $\mathrm{Bu}$ faaliyetler alüvyon akiferlerde alan ve hacim kaybına neden olarak yeraltısuyu miktarına, üzerindeki faaliyetlerin yeraltısuyuna kısa sürede ulaşması sonucunda da kalitesinin bozulmasına neden olmaktadır. Bu alüvyon akiferlerle ilgili çalışmalar çoğunlukla kuyu açılmasına ilişkin İller Bankası veya DSİ raporları şeklindedir. Bunların dışında kıyı şeridi boyunca Trabzon ili ve doğusundaki alüvyonların yeraltısuyu olanakları (Dilek, 1979), Aksu Deresi (Somel, 1988) ve Curi Irmağı (Yanbay, 1995) Alüvyonlarının hidrojeolojisi, Trabzon ili yeraltı ve yerüstü sularının kalitesi (Celep, 2009) gibi az sayıda akademik çalışma mevcuttur. Bu çalışmada bu tür kentsel faaliyetlerin Doğu Karadeniz kıyı akiferlerine geçmişten günümüze olumsuz etkileri araştırılmıştır.

\section{ÇALIŞMA ALANI}

Türkiye'nin kuzeydoğu kesiminde yer alan Doğu Karadeniz Havzasi; kuzeyde Karadeniz, batıda Yeşilırmak ve doğuda Çoruh Havzaları ile çevrelenmiştir. Havza, Ünye'den başlayarak Hopa'ya kadar uzanan ve Doğu Karadeniz Dağları ile sınırlandırılmış bir kuşağı kapsamaktadır (Şekil 1). Doğu Karadeniz Havzası Artvin (Hopa ve Arhavi ilçeleri), Rize, Trabzon, Gümüşhane (Torul ve Kürtün ilçeleri), Giresun ve Ordu illerini içerisine almaktadır. Toplam yağış alanı 22844 km² (İklim Değişikliğinin Su Kaynaklarına Etkisi Projesi, 2016) olan Doğu Karadeniz Havzası'nın yıllık ortalama yağış yüksekliği 1300 mm'dir. Havzanın en önemli akarsuyu 160 km uzunluğunda olan Harşit Çayı' dır. Diğer en önemli akarsular Curi Irmağı, Melet Irmağı, Bolaman Çayı, Elekçi Deresi, Turnasuyu, Pazarsuyu, Aksu Çayı, Yağlı Dere, Fol Deresi, Değirmendere (Maçka Deresi), Yanbolu Deresi, Manahoz Deresi (Gürçay), Solaklı Deresi, İyidere, Fırtına Deresi ve Kabisre Deresi' dir. Güney-kuzey yönünde uzanan akarsuların çoğu birbirinden bağımsız olarak kuzey yönünde Karadeniz'de sonlanmaktadır.

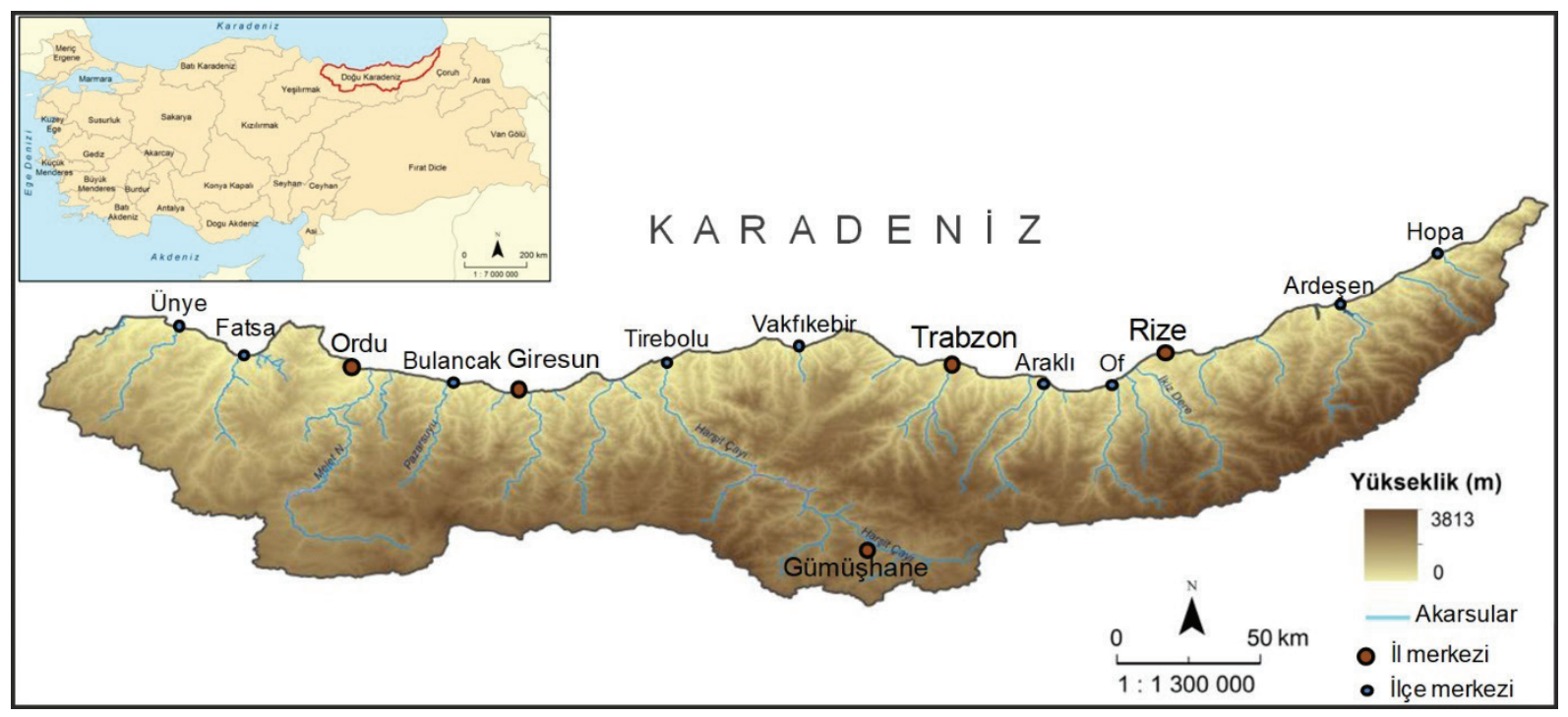

Şekil 1. Doğu Karadeniz Havzası'nın konumu

Figure 1. Location map of the Eastern Black Sea Basin 
Doğu Karadeniz Havzası, yıllık yağış miktarının Türkiye ortalamasının (623 mm) üzerinde olması, yüksek eğime sahip olmas1, akarsuların kısa mesafede yüksek düşümlere olanak vermesi, irili ufaklı birçok küçük akarsuyun, birbirinden bağımsız olarak Karadeniz'e boşalması, yaygın olarak volkanik birimlerin yüzeylenmesi gibi özellikleri ile kendine özgü karaktere sahiptir. Jeolojik ve topografik yapıya bağlı olarak, derelerin Karadeniz'e boşalım noktasına yakın bölgelerde, taşınan malzemelerin çökelmesi ile çok sayıda alüvyon akifer gelişmiştir. Akarsu vadilerinin genişlediği ve akışın yavaşladığı yerlerde silt, kum, çakıl ve küçük blok boyutunda malzemelerden oluşan alüvyon çökelleri oluşmuştur. Akışın hızlı olduğu vadilerin dar kesimlerinde ve vadi tabanında iri çak1l, blok ve büyük bloklardan oluşan malzemeler depolanmaktadır. Ayrıca bütün akarsulara yan kolların katıldığı kesimlerde ince kum, silt ve kil gibi ince malzeme birikimi olmaktadır. Doğu Karadeniz Havzası'nda DSI tarafindan rasatları devamlı yapılan kaynak suyu bulunmamaktadır.
Ancak özellikle volkanik kayaçların kırık ve çatlaklarından süzülen sulardan beslenen çok fazla küçük debili kaynaklar bulunmaktadır. $\mathrm{Bu}$ kaynaklar sürekli akan dereleri oluşturmakta ve beslemektedir.

\section{Jeolojik ve Hidrojeolojik Özellikler}

Doğu Karadeniz Havzası'nın kuzey kesimlerinde çoğunlukla bazalt, andezit, bazaltik- andezitik tüf ve aglomeralar, dasit ve riyodasit gibi volkanik kayaçlar yüzeylenmektedir. Bu volkanik kayaçlar yer yer kumtaşı, kumlu kireçtaşı, marn, kireçtaş1 gibi ara katkılar içermektedir. Güney kesimlerinde ise dağ silsilesini oluşturan granit, diyorit, granodiyorit gibi magmatik kayaçların oluşturduğu granitoyidler ile kireçtaşı ve fliş özelliğinde olan tortul kayaçlar yüzeylenir. Akarsu aşındırması ve tektonik etkinliğe bağlı olarak gelişmiş yaklaşık kuzey-güney uzanımlı vadilerin denize yakın kısımlarında taşıdıkları alüvyon malzemeler yüzeylenmektedir (Şekil 2).

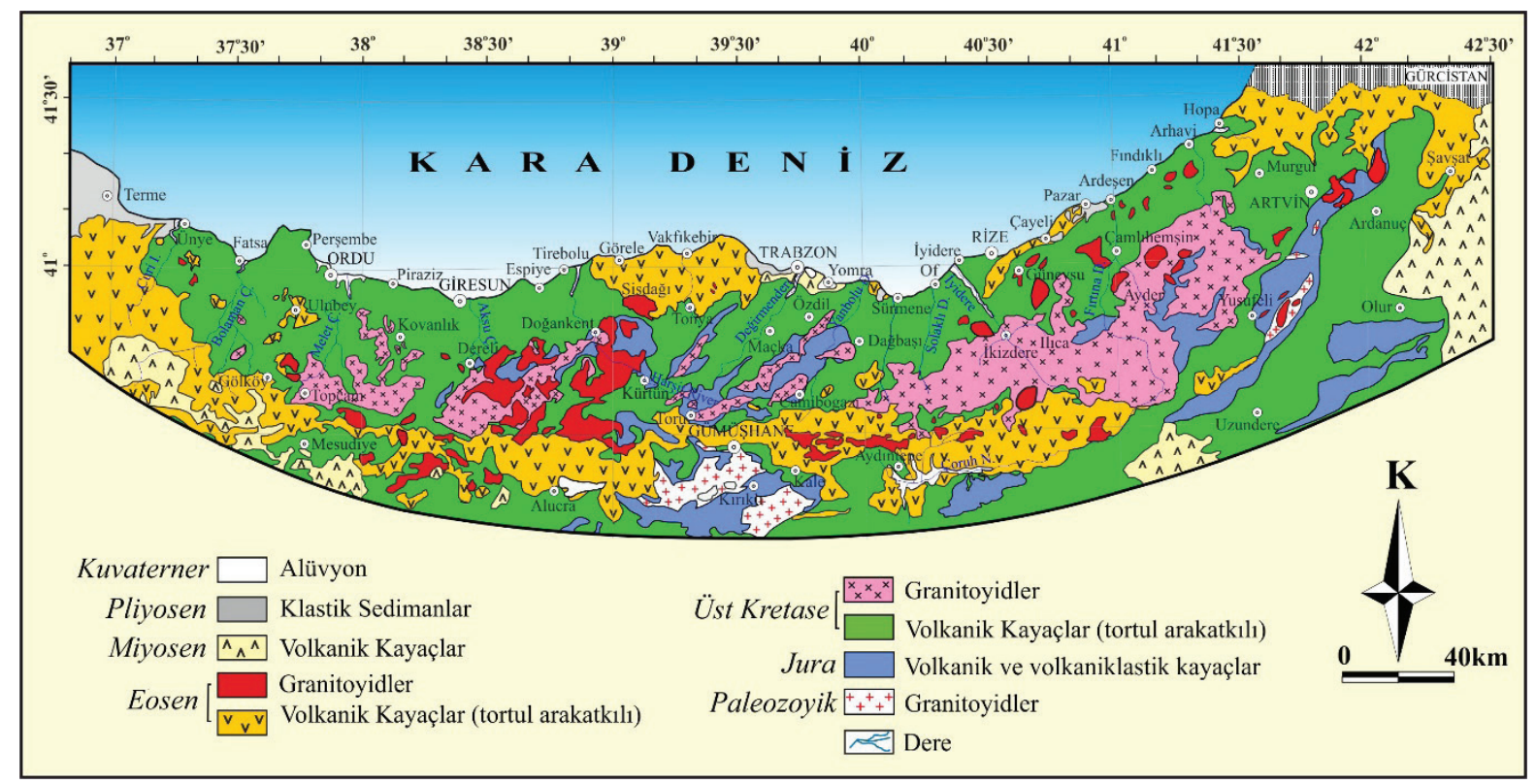

Şekil 2. Doğu Karadeniz Havzası'nın jeoloji haritası (Güven, 1993; Arslan vd., 2013; Yücel, 2013 ve Temizel vd., 2016'dan sadeleştirilerek)

Figure 2. Geological map of the Eastern Black Sea basin (Simplified from Güven, 1993; Arslan et al., 2013; Yücel, 2013 and Temizel et al., 2016) 
Karadeniz kıyı şeridi gerisinde tortul ara katkılı volkanik kayaçlar geniş yüzeylekler verir. Genellikle bazalt, andezit ve bazaltik, andezitik aglomeralar şeklinde bulunan volkanik kayaçlar yersel olarak farklı hidrojeolojik özelliklere sahiptir. Volkanik kayaçlarda yüzeyde çabuk soğuma ve gaz kaçışı soğuma çatlaklarının ve kabarcık şeklinde gözeneklerin oluşmasına sebep olmaktadır. Lav akıntıları sonucu oluşan volkanik kayaçlar çoğunlukla bloklu kaya kütlesi oluştururlar ve bu tür bazaltlarda çok yüksek bir yığınsal geçirgenlik oluşur (Freeze ve Cherry, 1979). Kül katmanları ve sokulum daykları gibi volkanik kayaçlarda ise hidrolik iletkenlik çok düşüktür (Fetter, 2001). Doğu Karadeniz kıyı şeridinde yüzeylenen volkanik kayaçlar litolojik olarak farklılık göstermesine rağmen çoğunlukla lav akıntıları sonucu oluşmuş bazaltlar, bazaltik aglomera ve tüfler şeklindedir. $\mathrm{Bu}$ volkanik kayaçların gözeneklilikleri tüflerde \%4-5 (Ersoy vd., 2014); bazaltlarda \%2-3 (Çevik, 2012) arasında değişir.

Kıy1 şeridinin daha güneyinde ve sarp topoğrafya ile yüzeylenen magmatik kayaçları genellikle granit, granodiyorit, diyorit ve monzonitler oluşturur. Çatlaksız olduklarında poroziteleri nadiren \%2'nin üzerinde (Freeze ve Cherry, 1979) olan bu tür magmatik kayaçlar çatlaklı olduklarında yüksek porozite değerlerine sahip olurlar. Çalışma alanında yüzeylenen magmatik kayaçlardan granit ve granodiyoritlerin poroziteleri \%0,6-1,2 arasındadır (Acar, 2015). Gözenek boyutlarının küçük ve gözeneklerin birbiri ile bağlantısız olmasından dolayı bu kayaların birincil geçirgenlikleri son derece düşüktür. $\mathrm{Bu}$ tür kaya örneklerinde yapılan ölçümler birincil geçirgenlik değerlerinin $10^{-11}-10^{-}$ ${ }^{13} \mathrm{~m} / \mathrm{s}$ arasında olduğunu göstermiştir (Freeze ve Cherry, 1979). Bu tür kayaçlarda yeraltısuyunun depolanabilmesi için çatlaklanma, faylanma veya ayrışma yoluyla gelişmiş açıklıkların bulunması gereklidir. Plütonik kayaçlarda yüzeyden itibaren birkaç on metrelik bazen yüz metrelik kısımda gelişen çatlaklılık durumlarından dolayı yüksek geçirgenlik gelişebilmektedir. $\mathrm{Bu}$ geçirgenlik artan derinliğe bağlı olarak azalmaktadır. Çatlaklı ve çatlakların birbirleriyle ilişkili oldukları alanlarda yeraltısuyu bulunduran volkanik kayaçlar çatlaksız oldukları alanlarda geçirimsiz özelliktedir. $\mathrm{Bu}$ ortamlardan yeraltısuyu elde edilmesi açılacak sondajın çatlakları kesmesi ile ilişkilidir Alüvyon akiferlerin beslenimi büyük çoğunlukla akıştan ve kısmen de çevresinde yüzeylenen volkanik kayaçlardan süzülme veya bu kayaçların üzerinde ayrışma ürünü olarak bulunan geçirimli kısımdaki yüzey altı akışından olmaktadır (Şekil 3). Alüvyonlardaki yeraltısuyu seviyesi genellikle akarsu seviyesinde veya çok sığ (0,3-1 m) derinliklerde olup, yeraltısuyu akımı yüzey suyuna benzer şekilde yaklaşık güneyden kuzeye doğrudur.

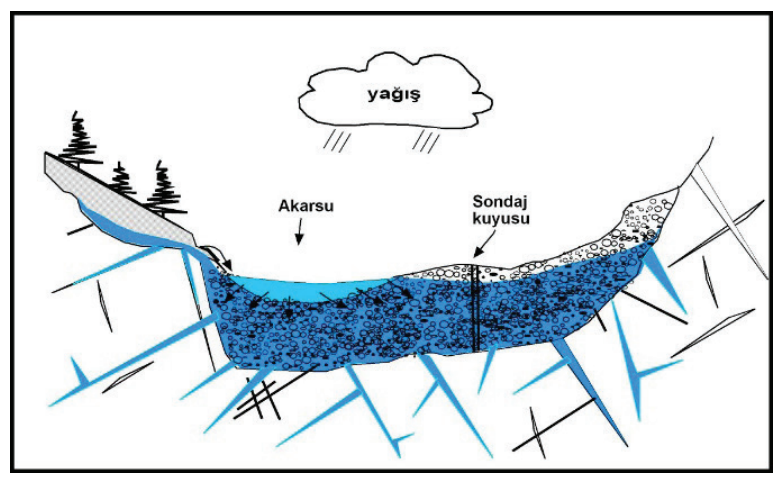

Şekil 3. Doğu Karadeniz kıyı akiferlerinin enine kesiti.

Figure 3. Cross section of the Eastern Black Sea coastal aquifers.

\section{Alüvyon Akiferler}

Doğu Karadeniz kıyı şeridi boyunca Hopa'dan başlayarak Samsun il sınırına kadar uzanan alanda yeraltısuyu bakımından önem taşıyan birimler akarsu alüvyonlarıdır. $\mathrm{Bu}$ bölgede her mevsim su taşıyan ancak debileri yıl içersinde değişiklik gösteren yaklaşık 100 civarında akarsu mevcuttur. Akarsuların taşıdığı alüvyon malzemeler yatak 
eğimlerinin düştüğü denize yakın kısımlarda vadi içerisinde depolanmıştır. Bu alüvyon malzemelerin kalınlıkları ve yayılımları da farklılık gösterir. Yayılımları ve kalınlıkları fazla olan alüvyonlar yeraltısuyu rezervi bakımından önem taşırken bir kısmı çok dar şeritler şeklinde yüzeylendiği ve kalınlıkları 1-3 m gibi az olduğu için ekonomik miktarda yeraltısuyu içermezler. Doğu Karadeniz Havzası'nda yer alan ve yeraltısuyu bakımından önemli olan alüvyonlar ve değişik kaynaklardan derlenen özellikleri Çizelge 1'de verilmiştir. Alüvyonların genişlikleri ve kalınlıkları kuzeyde deniz kıyısında en yüksek değerde iken güneye doğru gidildikçe azalmaktadır. Kıyı akiferlerinin herbiri için en düşük ve en yüksek kalınlık ve genişlik değerleri Çizelge 1'de verilmiştir. Uzunlukları $1 \mathrm{~km}$ ile 16,5 km arasında değişen alüvyonların genişlikleri $50 \mathrm{~m}$ ile $1500 \mathrm{~m}$, kalınlıkları $10 \mathrm{~m}$ ile $60 \mathrm{~m}$ arasındadır. Kil, silt, kum, çakıl ve blok karmaşığından oluşan heterojen yapılı alüvyonlar kısa aralıklarla yanal ve düşey yönlerde yapısal değişiklikler gösterir (Yavuz, 2004). Özellikle akarsuların yan kollarla birleşme yerlerinin yakınlarında silt ve kil gibi geçirimsiz özellikte olan ince malzeme birikimi akarsuyun diğer kesimlerine göre daha fazladır. Serbest akifer özelliğinde olan akarsu kıyı akiferlerinin bazılarında bantlar ve mercekler şeklinde biriken bu geçirimsiz malzemelerin kalınlıkları 1-10 m arasında değişmektedir.

Trabzon, Rize ve Artvin sınırları içerisinde kalan kıyı akiferlerini oluşturan alüvyon malzemelerin laboratuvarda hesaplanan porozite değerleri (n) \%18,6-27, geçirgenlik katsayıları (K) $10^{-3}-10^{-5} \mathrm{~m} / \mathrm{s}$ arasindadır (Dilek, 1979). Havzada kil, silt, kum, çakıl ve blok karışımından oluşan 40-50 adet kı1 akiferinde depolanan su hacmi porozite değerleri $\% 25$ alınıp ve akifer geometrisinden yararlanarak DSİ (2015) tarafından hesaplanmıştır. $\mathrm{Bu}$ hesaplamalara göre kıyı akiferlerinde depolanan su hacmi 0,5$24,45 \mathrm{hm}^{3}$ arasında değişmekte olup, toplam 238 $\mathrm{hm}^{3}$ 'tür. Havzada alüvyon akiferlerde açılan DSI tarafindan ruhsatlı toplam kuyu sayısı yaklaşık 660 adettir. Geçmiş yıllarda bu kıyı akiferlerinin bir kısmında, yerleşim alanlarının içme ve kullanma suyu ihtiyaçlarını karşılamak üzere 56 adet keson su kuyusu açılmıştır. Açılan keson su kuyularının derinlikleri 4-12 m; verimleri 5-57 1/s arasında değişmektedir (Yavuz, 2004). Zaman içinde akarsu akiferlerinin mansap kesimlerinde su sondaj kuyularının açılması sonucu keson kuyuların birçoğu terk edilmiştir. Sondaj kuyularında ölçülen statik su seviyeleri 1-10 m, dinamik su seviyeleri 4-30 m, kuyu verimleri ise 2-75 1/s arasında değişir (DSİ, 2015).

\section{Yeraltısuyu Kimyası}

Doğu Karadeniz Havzası alüvyon akiferlerinin tamamının su kimyası ve kalitesine yönelik ayrıntılı çalışmalar bulunmamaktadır. Ancak 2000 yılına kadar açılmış bazı kuyular için DSI Genel Müdürlügü̈nün verileri ile kimyasal açıdan bir sınıflama yapılmıştır (DSİ, 2015). Yapılan sinıflamaya göre Ordu (Curi, Bolaman, Melet, Turnasuyu, Civil), Giresun (Aksu, Harşit Çayı), Trabzon (Fol, Değirmendere, Yomra, Şana) alüvyon akiferlerinde açılan kuyu sularının genel olarak kimyasal açıdan $\mathrm{CaHCO}_{3}$ tipinde, tuzluluk açısından C2S1 sınıfında olduğu belirtilmiştir. 2000'li y1llarda Trabzon Değirmendere akiferinde yapılan çalışmalarda yeraltısuyunun sertlik değerinin yüksek olduğu $\left(33^{\circ} \mathrm{F}\right), \mathrm{Cr}$ konsantrasyonunun içme kullanma suyu yönetmeliğinde önerilen değerin üzerinde olduğu belirtilmiştir (Gültekin vd., 2005). Celep (2009) tarafından Trabzon il sınırları içerisinde kalan kıyı akiferlerinde su kalitesinin belirlenmesi amacıyla yapılan çalışmada, Kıtaiçi Yerüstü $\mathrm{Su}$ Kaynaklarının Sinıflarına (2004)'e göre yeraltısularının $\mathrm{Cu}, \mathrm{Pb}, \mathrm{Mn}$ ve $\mathrm{Ni}$ iz elementleri açısından II. sınıf (az kirlenmiş su), $\mathrm{PO}_{4}^{-3}, \mathrm{NO}_{2}^{-}$ve $\mathrm{Cl}^{-}$açısından III. sınıf (kirlenmiş su) ve IV. sınıf (çok kirlenmiş su) olduğu belirlenmiştir. 
Çizelge 1. Doğu Karadeniz Havzası kıyı akiferlerine ait bilgiler.

Table 1. Information about the coastal aquifers of the Eastern Black Sea Basin.

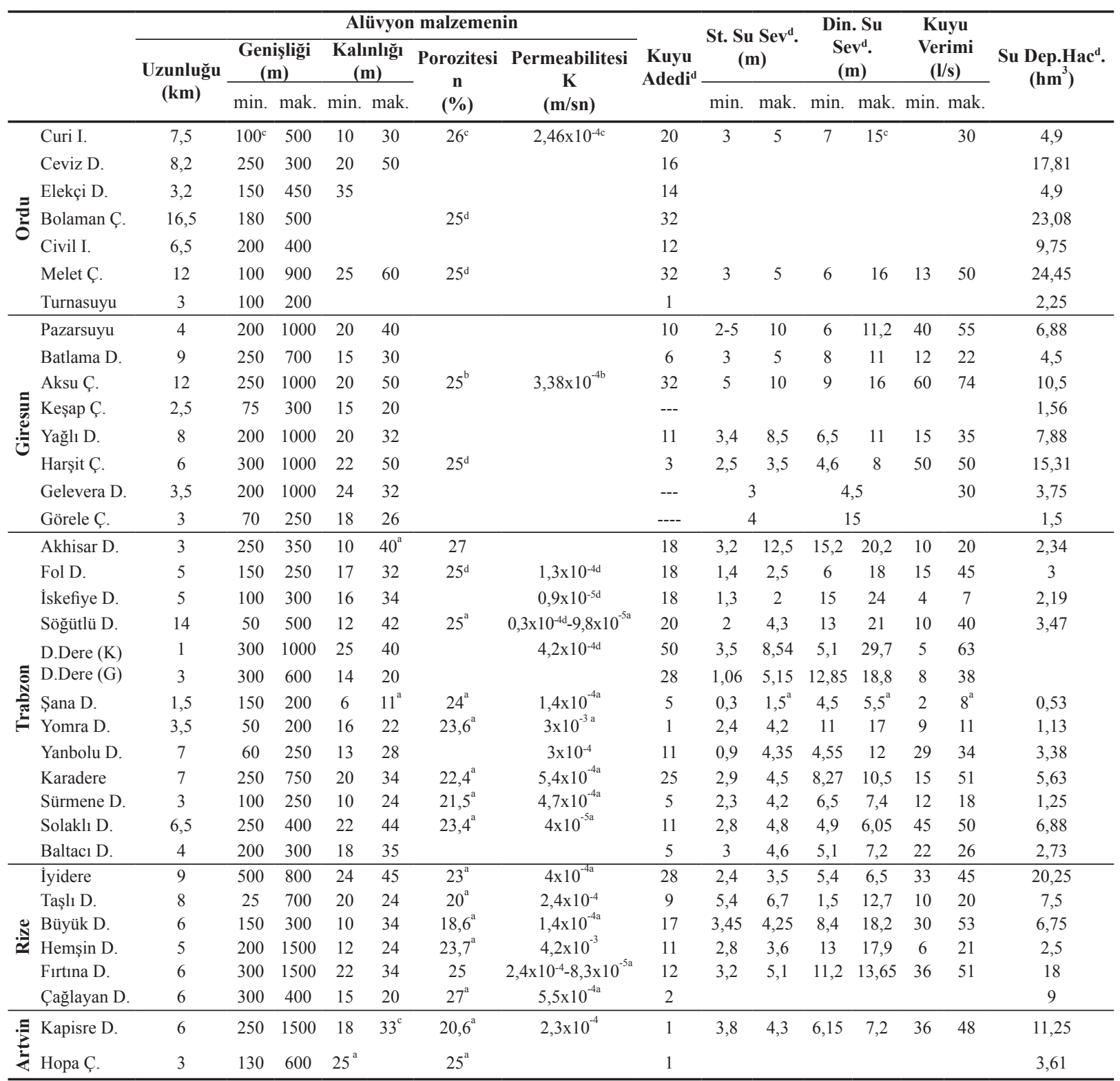

a: Dilek, 1979; b: Somel, 1988; c: Yanbay, 1995, d: DSİ, 2015

\section{KENTSEL FAALIYETLER}

Kırsal kesimden kentlere göçün artması kentlerde nüfus artışına neden olmuş ve imar alanları da genişlemiştir. Engebeli topoğrafyanın hakim olduğu Doğu Karadeniz Havzası'nda vadi içlerinde düz alanları oluşturan alüvyonlar, okul, yol, otopark, spor alanları gibi genel hizmet alanlarına, çeşitli depolama faaliyetleri, konaklama tesisleri, düğün salonları gibi konut dışı kentsel çalışma alanlarına ve sanayi siteleri gibi ticari faaliyet alanlarına ayrılmıştır. Engebeli bir topoğrafyaya sahip Doğu Karadeniz Havzası'nda sahilden iç kesimlere ulaşım çoğunlukla dere yatakları boyunca inşa edilen yollarla sağlanmaktadır. 
Vadilerin oldukça eğimli yamaçları yol inşaatını zorlaştırmakta, süresini uzatmakta ve maliyetini artırmaktadır. İlgili kurumlar için en uygun yol güzergâhı vadiler boyunca uzanan alüvyonların oluşturduğu az eğimli arazilerdir. 1990'l1 yıllara kadar taşkından etkilenmemek için kara yolları genellikle vadi yamaçlarında yapılan küçük kazılarla yamaca bitişik olarak inşa edilmiştir. Nüfusun ve trafikteki araç sayısının artması mevcut yolların genişlemesini gerektirmiş, dere kenarlarına taşkın koruma amaçlı beton-betonarme duvarlar inşa edilerek yollar alüvyonlar üzerinde genişletilmiştir.

Kırsal kesimden göçün etkisi ulaşımın kolay olabileceği alanlarda bölge okullarının inşasını gerektirmiş, bu okullar için çoğunlukla vadi tabanlarındaki alüvyon alanlar kullanılmıştır. Benzer şekilde konaklama tesisleri ve çeşitli toplantı faaliyetlerinin gerçekleştirileceği konut dışı yapılar da ulaşım rahatlığı nedeniyle alüvyon akiferler üzerine inşa edilmiştir. Özellikle 1990'l1 y1llarda konutlarda kömür kullanımının artış1 kentlerde kömür kırma eleme ve depolama tesislerinin artmasına neden olmuştur. $\mathrm{Bu}$ tür tesisler de alüvyon akiferler üzerinde inşa edilmiştir (Şekil 4). Kentlerde nüfusun hızlı artışı her türlü yapılaşmanın artmasına neden olmuştur. Özellikle inşaat sektöründeki artış beton santrallerinin çoğalmasına, beton için gerekli malzemenin üretiminin artmasına neden olmuş ve ulaşım rahatlığı nedeniyle beton santralleri de alüvyon akiferler üzerinde yerini almıştır. Vadi yamaçlarında açılan taş ocaklarından üretilen çakıl, kum gibi malzemeler de yine alüvyon akiferler üzerine depolanmaktadır. Kentlerde sanayileşmenin artması yeni sanayi sitelerinin oluşturulmasını gerektirmiştir. Sanayi siteleri için geçmişten günümüze akarsu yatakları kullanılmaktadır. İl ve ilçe bazındaki tüm yerleşim yerlerinin sanayi siteleri alüvyon akiferler üzerinde yer almaktadir.

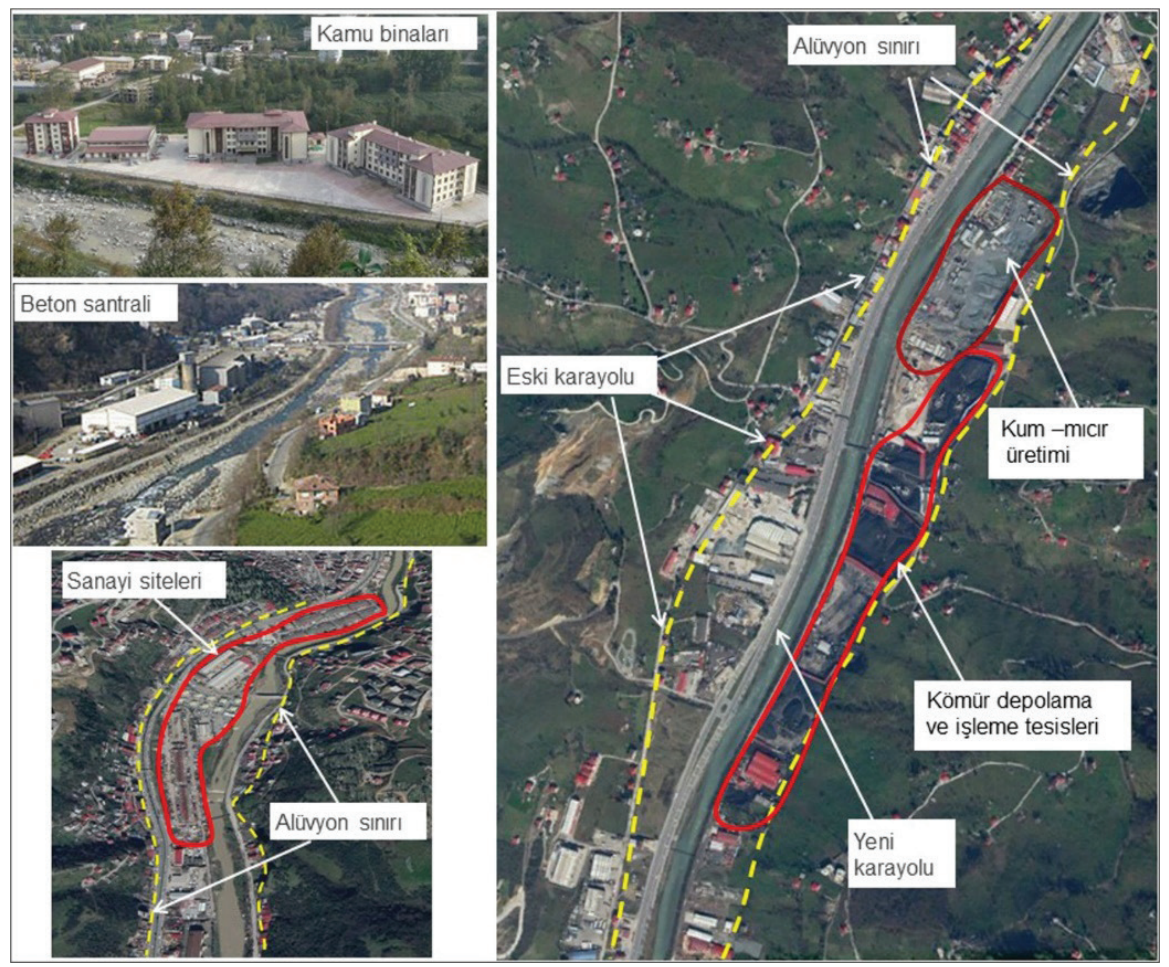

Şekil 4. Kıyı akiferleri üzerinde yer alan kentsel faaliyetler.

Figure 4. Urban activities on the coastal aquifers. 
İl merkezlerinin yer aldığı vadilerdeki akiferler kentleşmenin yoğun baskısı altındadır. Ordu il merkezinin yerleşim alanında yer alan Melet ve Civil alüvyonlarının büyük bir kısmı çok yoğun yapılaşmaya maruz kalmıştır. Benzer şekilde Giresun ili yerleşim alanında kalan Batlama, Aksu ve Keşap alüvyonları da kentleşmenin yoğun olduğu akiferlerdir. Trabzon il yerleşim alanı içerisinde kalan ve 1992 yılına kadar Trabzon ilinin içme ve kullanma suyunu sağlayan Değirmendere alüvyonları ise tamamen kentleşmenin etkisi altında kalmış ve yeraltısuyu sağlayan kuyular terk edilmiştir. Diğer alüvyon akiferlerin de çoğunluğu ilçe merkezlerinin yerleşim alanı içerisinde kalmakta ve akiferler üzerindeki kentsel baskılar giderek artmaktadır. Kentleşmenin etkilerinin en az olduğu akiferler Curi, Yağlidere, Gelevera, Akhisar, Yanbolu, Baltacı, İyidere ve Firtına akiferleridir. Bunlardan Curi, Yağlıdere, İyidere ve Fırtına akiferlerinin yeraltısuyu bulundurma kapasiteleri diğerlerine göre fazladır.

\section{SONUÇLAR VE TARTIŞMA}

Doğu Karadeniz Havzası'nda akarsu vadileri boyunca yüzeylenen alüvyonlar havzanın yeraltısuyu taşıyan tek akiferleridir. Genişlikleri 50-1500 m, uzunlukları 3-16,5 km ve kalınlıkları $10-50 \mathrm{~m}$ arasındadır. Porozite değerleri \%19 ile $\% 27$, geçirgenlik katsayıları $10^{-3}-10^{-5} \mathrm{~m} / \mathrm{s}$ arasında olan akiferlerde depolanan toplam su hacmi minimum $238 \mathrm{hm}^{3}$ 'tür. Yayılımları ve kalınlıkları kuzeyden güneye doğru azalan bu akiferlerin beslenimi büyük çoğunlukla üzerlerinden akan akarsulardan süzülme ile gerçekleşir ve yeraltısuyu akımı akarsuya uyumlu olarak yaklaşık güneyden kuzeye doğrudur.

Havzada alüvyon akiferler vadileri drene eden akarsuların etrafında dar şeritler şeklinde yüzeylenmektedir. Ünye'den Hopa'ya kadar uzanan kıyı şeridi boyunca hemen hemen her vadi boyunca bir yerleşim yeri bulunmaktadır.
$\mathrm{Bu}$ yerleşim yerleri iç kesimlere ulaşım için vadileri kullanmaktadır. Ulaşım ağlarını oluşturan karayollarının bir kısmı her bir vadide alüvyon akiferler üzerinde yer almaktadır. Ortalama yol genişliği ve akifer üzerindeki uzunlukları dikkate alındığında bu ulaşım ağının akiferler üzerinde yaklaşık \% 10-25'lik alan kapladığ görülmektedir. Karayollarının üzerinden geçtiği birimlerin taşıdığı yeraltısularına etkileri olabileceği gibi yeraltısularının da karayollarına etkileri olmaktadır (Brencic, 2006). Karayolları geçirimsiz yüzey oluşturarak akiferin beslenmesini engellediği gibi yol inşasında ve trafikte araçlardan çevreye yayılan ağır metal, petrol türevleri, çeşitli organik maddeler ve tuzlar aracılığıyla da yeraltısuyu kirlenmesine neden olmaktadır (Choi vd., 2005; Leitao, 2005; McGrane vd., 2014). Karayollarının inşası esnasında yapılan kazılar ve beton perde gibi inşaatlar yeraltısuyu beslenmesini ve hareketini engellemekte, yol için kullanılan malzeme ek yük oluşturarak akifer basıncını azaltacak şekilde etki etmektedir. Doğu Karadeniz Havzası kıyı akiferleri akarsudan, yağıştan ve yamaçlardan süzülen yüzey ve yüzeyaltı suları ile beslenmektedir. Yamaca bitişik inşa edilen karayolları akifer üzerinde geçirimsiz zon oluşturarak yağış yoluyla yüzeyden ve yamaçlardan beslenmeyi engellemektedir. Ayrıca geçirimsiz yüzey oluşturan karayolları havzanın üst kesimlerinde meydana gelen yağışların hızlı bir şekilde akarsuya ulaşmasını sağlayarak havzanın aşağı kesimlerinde oluşacak taşkınlara katkıda bulunmaktadır. Akarsuyun rejimi bozulduğu için havzanın iç kesimlerinde alüvyon birikiminin azalmasina veya yok olmasina neden olmaktadır.

Havzadaki alüvyon akiferler havzanın en önemli yeraltısuyu kaynaklarıdır. Arıtılmış yüzey suyunu kullanan Rize ve Trabzon il merkezleri dışındaki tüm il ve ilçeler su gereksinimini karşılamak amacıylayeraltısuyunu kullanmaktadır. Ancak şehir merkezlerindeki nüfus artışı yerleşim alanlarının alüvyonlar üzerinde genişlemesine neden olmaktadır. Havzada yer alan alüvyon 
akiferlerin tamamında son yıllarda özel ve kamuya ait konut artışı olduğu görülmektedir. Kent merkezinden kısmen uzaklaştıkça sanayi siteleri ve malzeme depolama alanları da alüvyonlar üzerinde yer almaktadır. Özellikle kömür kırma-eleme-paketleme işlemi yapan tesislerin gözenekliliği yüksek olan bu alüvyon akiferler üzerinde yer alması su kalitesini de tehdit etmektedir. Yayılımları ve derinlikleri küçük olan bu alüvyon akiferlerin üzerine yapılacak her türlü yap1 akiferde alan ve hacim kaybına neden olmakta, yeraltısuyu beslenmesini olumsuz etkilemekte ve akifer rezervinde azalmalara neden olmaktadır.

Eski yıllara ait haritalar ve fotoğraflar incelendiğinde alüvyon akiferler üzerine inşa edilen konut dışı yapıların sayısının gün geçtikçe $\operatorname{arttığ1~görülmektedir.~Uydu~fotoğraflarından~}$ yararlanarak bu tür yapıların alüvyon akiferler üzerinde kapladıkları alanlar yaklaşık olarak belirlenmeye çalışılmıştır. Her bir havzada farklılık göstermekle birlikte akifer alanının yaklaşık \%1030’unu bu tür yapıların kapladığı belirlenmiştir. $\mathrm{Bu}$ tür yapılaşmalar kazı gerektirdiği için alüvyonda hacim azalmasına ek yük oluşturarak gözenekliliğin düşmesine neden olmaktadır.

Havzada bazı vadilerde bulunan kömür depolama alanlarının da bulunduğu havzalarda yaklaşık \%3-5' lik bir alan kapladı ğı belirlenmiştir. Alüvyon malzeme üzerinde ek yük oluşturan bu tür yapılar alüvyon malzemenin gözenekliliğini azaltarak depolanan yeraltısuyu miktarını olumsuz etkilemektedir. $\mathrm{Bu}$ alanlardan akiferlere ulaşan sızıntı suyunun yeraltısuyunun kalitesi üzerine nasıl bir etkisi olduğu yönünde çalışmalar bulunmamaktadır. Ancak akiferlerin porozitelerinin yüksek ve yeraltısuyunun çok sı ğ olduğu dikkate alınırsa su kalitesi üzerine de olumsuz etkilerinin olabileceği göz ard1 edilmemelidir. Ayrıca akarsu yataklarında veya yakınlarında inşa edilen her türlü yapının akiferlere dolaylı etkileri bulunmaktadır. Taşkından korunmak amaçlı yapılan beton duvarlar jeolojik tarihçe boyunca devam eden alüvyon birikimi sürecini kesintiye uğratmaktadır.

Doğu Karadeniz kıy akiferlerinde mevcut kentsel faaliyetler incelendiğinde akiferlerin tamamında yapılaşmanın olduğu, çoğunluğunda çeşitli depolama faaliyetlerinin, yarısında ise sanayi sitelerinin yer aldığ 1 , bir k1sminda da beton üretim faaliyetlerinin olduğu görülmektedir (Çizelge 2). Kentleşmenin getirdiği bu tür baskılar giderek artmakta ve akiferlerin sürdürülebilir kullanımını olumsuz yönde etkilemektedir. Bu etkilerin sonuçları ne yazık ki Trabzon ve Rize il merkezlerinin içmekullanma suyunu sağlayan Değirmendere ve Taşlıdere akiferlerinde yeraltısuyu kullanımını sonlandırmıştır. Yeraltısuyu kullanımı devam eden diğer akiferlerde, akiferin beslenmesini ve su kalitesini etkileyecek faaliyetlerin artarak devam ettiği görülmektedir. Yıllık yağış miktarının ve akarsudan beslenmenin fazla olması ve yağışın kısa sürede akifere ulaşması nedeniyle henüz kimyasal açıdan önemli bir kirlilik görülmemektedir. Ancak birçok kuyunun yerleşim yeri içerisinde kalması sebebiyle, Giresun Pazarsuyu akiferinde ise mangan konsantrasyonun fazla olması nedeniyle kuyuların kullanım dışı bırakıldığı DSİ 22. Bölge Müdürlüğü elemanlarınca belirtilmiştir. Akiferler üzerindeki bu tür faaliyetler devam ettikçe ileriki yıllarda yeraltısuyu kirliliği de dikkat çekecek boyutlara ulaşacaktır. Kentleşmenin etkisi altında kalan Melet, Civil ve Pazarsuyu (Ordu), Batlama ve Keşap (Giresun) akiferlerinin sürdürülebilir kullanımı için kentsel faaliyetlerin etkilerinden korunmaları önemlidir. Temiz suya olan gereksinimin gün geçtikçe arttığı dikkate alınırsa Doğu Karadeniz havzasındaki bu kısıtlı akiferlerin sürdürülebilir kullanımı için kentleşmenin getirdiği bu tür baskıların önlenmesi ve/veya kontrol altına alınması gereklidir. Gerektiği gibi korunup takip edilmezse ileride kullanacak temiz ve kaliteli suya sahip olmak oldukça zor veya pahalı olacaktır. Ayrıca akarsuların akış rejimine yapılacak herhangi bir müdahalenin 
büyük oranda akarsu akışından beslenen alüvyon akiferlerin beslenmesine olumsuz etki yapacağı da unutulmamalıdır.

Havzadaki yerel yönetimler kent merkezlerindeki artan nüfusun su gereksiniminin gelecek yıllarda bu alüvyonlarda depolanan yeraltı sularıyla karşılanamayacağını düşünerek ileriki yıllar için yüzey sularının depolanıp arıtılarak kullanılması yönünde planlamalar yapmaktadırlar. Ancak akarsuların debi ve kalite bakımından mevsimsel değişiklik göstermeleri ve her türlü kirlenmeye açık oldukları dikkate alınırsa alüvyon akiferlerin ve mevcut kuyuların gerekli durumlarda kullanılabilmeleri için korunmaları son derece önemlidir.

\section{EXTENDED SUMMARY}

All living organisms need water from the hydrological cycle for their living activities. However, the amount of water per capita will be reduced in future years, since water demands of the growing population will be met by the constant amount of water in the cycle. Fresh water resources, with a ratio of about $3 \%$ in the water cycle, are increasingly polluted and the amount of water available is reduced over time. As a result of the rapid growth of the world population, industrialization and expansion of water use, water consumption in the world is increasing rapidly.

Çizelge 2. Doğu Karadeniz kıyı akiferlerini etkileyen kentsel faaliyetler.

Table 2. Urban activities affecting the Eastern Black Sea coastal aquifers.

\begin{tabular}{|c|c|c|c|c|c|c|c|c|}
\hline & \multirow{2}{*}{ Akifer adı } & \multirow{2}{*}{ Ulaşım } & \multicolumn{2}{|c|}{ Konutlașma } & \multirow{2}{*}{$\begin{array}{l}\text { Sanayi } \\
\text { siteleri }\end{array}$} & \multirow{2}{*}{$\begin{array}{l}\text { Kömür } \\
\text { işleme }\end{array}$} & \multirow{2}{*}{$\begin{array}{c}\text { Beton } \\
\text { üretimi }\end{array}$} & \multirow{2}{*}{$\begin{array}{c}\text { Malzeme } \\
\text { depolanması }\end{array}$} \\
\hline & & & Özel & Kamu & & & & \\
\hline \multirow{7}{*}{ 롤 } & Curi & $\mathrm{x}$ & $\mathrm{X}$ & $\mathrm{X}$ & & & & \\
\hline & Ceviz & $\mathrm{x}$ & $\mathrm{x}$ & & & $\mathrm{x}$ & & $\mathrm{x}$ \\
\hline & Elekçi & $\mathrm{x}$ & $\mathrm{x}$ & $\mathrm{x}$ & & & & \\
\hline & Bolaman & $\mathrm{x}$ & $\mathrm{x}$ & & & & & $\mathrm{x}$ \\
\hline & Civil & $\mathrm{x}$ & $\mathrm{x}$ & $\mathrm{x}$ & & & & \\
\hline & Melet & $\mathrm{x}$ & $\mathrm{x}$ & $\mathrm{x}$ & $\mathrm{x}$ & & & $\mathrm{x}$ \\
\hline & Turnasuyu & $\mathrm{x}$ & $\mathrm{x}$ & & & & & \\
\hline \multirow{8}{*}{ 声 } & Pazarsuyu & $\mathrm{x}$ & $\mathrm{X}$ & & & & & \\
\hline & Batlama & $\mathrm{x}$ & $\mathrm{x}$ & $\mathrm{x}$ & $\mathrm{x}$ & & & $\mathrm{x}$ \\
\hline & $\mathrm{Aksu}$ & $\mathrm{x}$ & $\mathrm{x}$ & $\mathrm{x}$ & & & & $\mathrm{x}$ \\
\hline & Keşap & $\mathrm{x}$ & $\mathrm{x}$ & $\mathrm{x}$ & & & & \\
\hline & Yağli & $\mathrm{x}$ & $\mathrm{x}$ & $\mathrm{x}$ & & & & \\
\hline & Gelevera & $\mathrm{x}$ & $\mathrm{x}$ & & & & $\mathrm{x}$ & $\mathrm{x}$ \\
\hline & Harşit & $\mathrm{x}$ & $\mathrm{x}$ & & & & $\mathrm{x}$ & $\mathrm{x}$ \\
\hline & Görele & $\mathrm{x}$ & $\mathrm{x}$ & & & & & $\mathrm{x}$ \\
\hline \multirow{13}{*}{ 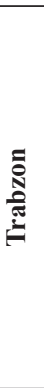 } & Akhisar & $\mathrm{x}$ & $\mathrm{x}$ & & & & & \\
\hline & Fol & $\mathrm{x}$ & $\mathrm{x}$ & $\mathrm{x}$ & & & & \\
\hline & İskefiye & $\mathrm{x}$ & $\mathrm{x}$ & & & & & \\
\hline & Söğütlü & $\mathrm{x}$ & $\mathrm{x}$ & $\mathrm{x}$ & $\mathrm{x}$ & & & $\mathrm{x}$ \\
\hline & D. Dere(Kuzey) & $\mathrm{x}$ & $\mathrm{x}$ & $\mathrm{x}$ & $\mathrm{x}$ & & & \\
\hline & D. Dere(Güney) & $\mathrm{x}$ & $\mathrm{x}$ & & & $\mathrm{x}$ & $\mathrm{x}$ & $\mathrm{x}$ \\
\hline & Şana & $\mathrm{x}$ & $\mathrm{x}$ & & $\mathrm{x}$ & & & \\
\hline & Yomra & $\mathrm{x}$ & $\mathrm{x}$ & & & & & $\mathrm{x}$ \\
\hline & Yanbolu & $\mathrm{x}$ & $\mathrm{x}$ & & & & & \\
\hline & Karadere & $\mathrm{x}$ & $\mathrm{X}$ & $\mathrm{x}$ & & & $\mathrm{x}$ & $\mathrm{x}$ \\
\hline & Sürmene & $\mathrm{x}$ & $\mathrm{x}$ & $\mathrm{x}$ & $\mathrm{x}$ & & & $\mathrm{X}$ \\
\hline & Solaklı & $\mathrm{x}$ & $\mathrm{x}$ & $\mathrm{x}$ & $\mathrm{x}$ & & & $\mathrm{x}$ \\
\hline & Baltaci & $\mathrm{X}$ & $\mathrm{X}$ & & & & & \\
\hline \multirow{6}{*}{ 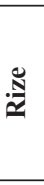 } & İyidere & $\mathrm{X}$ & $\mathrm{X}$ & & $\mathrm{x}$ & & $\mathrm{x}$ & $\mathrm{x}$ \\
\hline & Taşlı & $\mathrm{x}$ & $\mathrm{x}$ & $\mathrm{x}$ & $\mathrm{x}$ & $\mathrm{x}$ & $\mathrm{x}$ & $\mathrm{x}$ \\
\hline & Büyük & $\mathrm{x}$ & $\mathrm{x}$ & $\mathrm{x}$ & $\mathrm{x}$ & & $\mathrm{x}$ & \\
\hline & Hemşin & $\mathrm{x}$ & $\mathrm{x}$ & $\mathrm{x}$ & & & & $\mathrm{x}$ \\
\hline & Firtına & $\mathrm{x}$ & $\mathrm{x}$ & & $\mathrm{x}$ & & & \\
\hline & Cağlayan & $\mathrm{x}$ & $\mathrm{x}$ & $\mathrm{x}$ & & & & \\
\hline \multirow{2}{*}{$\sum_{2}^{\equiv}$} & Kapisre & $\mathrm{x}$ & $\mathrm{x}$ & & $\mathrm{x}$ & $\mathrm{x}$ & & \\
\hline & Нора & $\mathrm{x}$ & $\mathrm{X}$ & $\mathrm{x}$ & $\mathrm{X}$ & $\mathrm{x}$ & & \\
\hline
\end{tabular}


Alluvial materials deposited in almost every valley along the coastline from Ünye to Hopa have different widths and thicknesses. While the width and thickness of alluvium deposits are highest in the north along coast line, they decrease towards the south. Alluvium aquifers vary in length from $1 \mathrm{~km}$ to $16.5 \mathrm{~km}$ and have widths of $50-1500 \mathrm{~m}$ and thicknesses of $10-60 \mathrm{~m}$. The volume of water stored in these coastal aquifers ranges from 0.5 to $24.45 \mathrm{hm}^{3}$, with a total of $238 \mathrm{hm}^{3}$ (Table 1). The city and town centers in the Eastern Black Sea region obtain all of their drinking and potable water requirements from the aquifers formed by alluvium. Almost all of the town centers still use groundwater, while Rize and Trabzon cities have started to use treated surface water. Giresun city obtains all of its water from groundwater, whereas Ordu city obtains a large part of its drinking water from groundwater (DSI, 2015).

The increase in migration from rural to urban areas has caused population growth in cities and necessitated expansion of urban areas. Alluvium that forms flat areas inside valleys in the Eastern Black Sea basin, which has rugged topography, are divided into general service areas such as schools, roads, car parks, sports fields, various storage activities, accommodation facilities, urban facility areas such as wedding halls and commercial areas such as industrial sites. Growth of cities creates undesirable stress on natural resources such as water resources, hydrological dynamics and environmental quality. Numerous studies have examined the impact of urban activities on aquifers, where the water needs of many large cities are supplied by groundwater. Most of these studies were conducted on the deterioration of groundwater quality (Long and Saleem, 1974; Fusillo et al., 1985; Nazari et al. 1993; Diaz-Fierros et al., 2002; Choi et al., 2005; McGrane et al., 2014). Studies about the change in groundwater level (Brassington and Rushton, 1987; Knipe et al., 1993; Trivedi et al., 2001) and the effects of urban areas on hydrological processes (Niemczynowicz 1999; Vörösmarty et al., 2000; Naik et al., 2008; Hayashi et al., 2009; Fletcher et al., 2013; McGrane, 2016) are becoming increasingly important.

Construction is observed on all of the Eastern Black Sea coastal aquifers, including the majority of various storage activities, half of the industrial sites and some concrete production activities (Table 2). Such stresses arising from urbanization are increasing and adversely affect the sustainable use of aquifers. The results of these effects unfortunately ended the use of groundwater from the Değirmendere and Taşlidere aquifers. In other aquifers where groundwater usage is continuing, activities that will affect the recharging of the aquifer and water quality continue to increase. Melet, Civil, Pazarsuyu (Ordu), Batlama and Keşap (Giresun) aquifers, which are all located within the settlement area, are mostly influenced by urban activities. The aquifers of Curi, Yağlidere, Gelevera, Akhisar, Yanbolu, Baltacl, Iyidere and Firtına are less affected by urban activities. Among them, Curi, Yağlidere, Iyidere and Firtına are aquifers with high groundwater capacities. Considering that the need for fresh water is increasing day by day, such stresses caused by urbanization should therefore be prevented and/ or controlled to ensure the sustainable use of these aquifers in the Eastern Black Sea Basin.

\section{KATKI BELİRTME}

Yazarlar makaledeki verilerin sağlanması konusundaki yardımlarından dolayı DSİ 22. Bölge Müdürlüğü elemanlarından Jeoloji Mühendisi Songül CEVAHİR'e ve Jeoloji Mühendisi Güven Köksal KUTLU'ya teşekkür eder.

\section{ORCID}

Fatma Gültekin (D) https://orcid.org/0000-0002-6409-7054

Esra Hatipoğlu Temizel (D) https://orcid.org/0000-0001-7680-1152 


\section{DEĞINILEN BELGERLER / REFERENCES}

Acar, S., 2015, Petrografik ve Fiziksel Özelliklerin Granitik Kayaçların Dayanımına Etkisinin Araştırılması. Karadeniz Teknik Üniversitesi, Fen Bilimleri Enstitüsü, Trabzon, Yüksek Lisans Tezi, $154 \mathrm{~s}$, (yayımlanmamış).

Arslan, M., Temizel, İ., Abdioğlu, E., Kolaylı, H., Yücel, C., Boztuğ, D., Şen, C. 2013. ${ }^{40} \mathrm{Ar}-$ ${ }^{39} \mathrm{Ar}$ dating, whole-rock and $\mathrm{Sr}-\mathrm{Nd}-\mathrm{Pb}$ isotope geochemistry of post-collisional Eocene volcanic rocks in the southern part of the Eastern Pontides (NE Turkey): Implications for magma evolution in extension-induced origin. Contribution to Mineralogy and Petrology, 166, 113-142.

Brassington, F. K., Rushton, K., 1987. Rising water table in central Liverpool. Quarterly Journal of Engineering Geology, 20, 151-158.

Brencic, M., 2006. Groundwater and highways interaction: past and present experiences of highway construction in Slovenia. Environmental Geology, 49, 804-813.

Celep, S., 2009. Trabzon İli Yeraltı ve Yerüstü Sularının Hidrojeolojik, Hidrojeokimyasal İncelemesi ve Su Kalitesinin İzlenmesi. Karadeniz Teknik Üniversitesi, Fen Bilimleri Enstitüsü, Trabzon, Yüksek Lisans Tezi, 165 s., (yayımlanmamış).

Choi, B., Yun, S., Yu, S., Lee, P., Park, S., Chae, G., 2005. Hydrochemistry of urban groundwater in Seoul, South Korea: effects of land use and pollutant recharge. Environmental Geology Journal, 48 (8) 979-990.

Çevik, L., 2012. Aydınlıkevler (Trabzon) Yöresindeki Bina Temel Zemininin Jeoteknik Özelliklerinin Araştırılması. Karadeniz Teknik Üniversitesi, Jeoloji Mühendisliği Bölümü, Trabzon, Lisans Tezi, 32 s., (yayımlanmamış).

Diaz-Fierros, T.F., Puerta, J., Suarez, J., Diaz-Fierros, F.V., 2002. Contaminant loads of CSOs at the wastewater treatment plant of a city in NW Spain. Urban Water, 4 (3) 291-299.

Dilek, R., 1979. Trabzon-Hopa Kiyı Şeridinin Yeraltı Suyu Olanakları, Karadeniz Teknik Üniversitesi Basımevi, Trabzon, No: 99, 103 s., (yayımlanmamış).

DSI, 2015. Devlet Su İşleri 22. Bölge Müdürlüğü, Doğu Karadeniz Havzası Master Plan Çalışmaları
İşi, Doğu Karadeniz Havzası Hidrojeoloji Raporu, $551 \mathrm{~s}$, (yayımlanmamış).

Ersoy, H., Yalçınalp, B., Babacan, A.E., 2014. Sarraftepe (Trabzon) Tefrit Silinin Jeolojik ve Jeomekanik Özelliklerinin Araştırılması. Jeoloji Mühendisliği Dergisi, 38 (1) 39-50.

Fetter, C.W., 2001. Applied Hydrogeology. PrenticeHall, Inc., New Jersery, USA, 612 s.

Fletcher, T.D., Andrieu, H., Hamel, P., 2013. Understanding, management and modelling of urban hydrology and its consequences for receiving waters: a state of the art. Advances in Water Resources, 51, 261-279.

Foster, S.S.D., Lawrence, A.R., Morris, B.M., 1998. Groundwater in urban development, Assessing Management Needs and Formulating Policy Strategies. World Bank Technical Paper no 390, Washington DC., 74 s., (yayımlanmış).

Freeze, R.A., Cherry, J.A., 1979. Groundwater. Prentice-Hall, New Jersey, USA, 562 s.

Fusillo, T.V., Hockreiter, J.J., Lord, D.G., 1985. Distribution of volatile organic compounds in a New Jersey coastal plain aquifer. Ground Water, 23, 354-360.

Gültekin F., Dilek, R., Firat Ersoy, A., Ersoy, H., 2005. Aşağ1 Değirmendere (Trabzon) Havzasındaki Suların Kalitesi. Jeoloji Mühendisliği Dergisi, 29 (1) 21-35.

Güven, İ.H., 1993. Doğu Pontidlerin Jeolojisi ve 1/250.000 Ölçekli Kompilasyonu. Maden Tetkik Arama Yayınları, Ankara, 65 s.

Hayashi, T., Tokunaga, T., Aichi, M., Shimada, J., Taniguchi, M., 2009. Effects of human activities and urbanization on groundwater environments: An example from the aquifer system of Tokyo and the surrounding area. Science of the Total Environment 407 (9), 3165-3172.

İklim Değişikliğinin Su Kaynaklarına Etkisi Projesi, 2016. T.C. Orman ve Su İşleri Bakanlığı, Su Yönetimi Genel Müdürlüğü, Ankara, İklim Değişikliğinin $\mathrm{Su}$ Kaynaklarına Etkisi Projesi Nihai Raporu, Ek 24-Doğu Karadeniz Havzas1, $120 \mathrm{~s}$, (yayımlanmamış).

Knipe, C.V., Lloyd, J.W., Lerner, D.N., Gresswell, R., 1993. Rising groundwater levels in Birmingham and the engineering implications. Construction 
Industry Research and Information Association Special Publication, 92, 114 s.

Leitao, T.E., 2005. Impact of road runoff in soil and groundwater. Synthesis of Portuguese and other European case-studies. The Fourth Inter-Celtic Colloguium on Hydrology and Managemet of Water Resources, Guimaraes, Portugal, July, 1114, 2005.

Long, D.T., Saleem, Z.A., 1974. Hydrogeochemistry of carbonate groundwaters of an urban area. Water Resources Research, 10, 1229-1238.

McGrane, S.J., Tetzlaff, D., Soulsby, S., 2014. Influence of lowland aquifers and anthropogenic impacts on the isotope hydrology of contrasting mesoscale catchments. Hydrological Processes, 28 (3) 793808.

McGrane, S.J., 2016. Impacts of urbanisation on hydrological and waterquality dynamics, and urban water management:a review. Hydrological Sciences Journal, 61 (13), 2295-2311.

Naik, P.,K., Tambe J.A., Dehury, B.N., Tiwari, A.N., 2008. Impact of urbanization on the groundwater regime in a fast growing city in central India. Environmental Monitoring and Assessment, 146, 339-373.

Nazari, M.M., Burston, M.W., Bishop, P.K., Lerner, D.N., 1993. Urban ground-water pollution: A case study from Coventry, United Kingdom. Ground Water, 31 (3) 417-424.

Niemczynowicz, J., 1999. Urban hydrology and water management - Present and future challenges. Urban Water, 1 (1) 1-14.

Somel, N., 1988. Aksu Vadisi (Giresun) Alüvyonlarının Hidrojeolojisi. Karadeniz Teknik Üniversitesi, Fen Bilimleri Enstitüsü, Trabzon, Yüksek Lisans Tezi, 46 s., (yayımlanmamış).
Temizel, İ., Arslan, M., Yücel, C., Abdioğlu, E., Ruffet, G., 2016. Geochronology and geochemistry of Eocene-aged volcanic rocks around the Bafra (Samsun, N Turkey) area: Constraints for the interaction of lithospheric mantle and crustal melts. Lithos, 258-259, 92-114.

Trivedi, S.M., Yadav, B., Gupta, R.N., Chandrasekharan, H., Ramachandran, K, 2001. Effects of urbanization on changes in groundwater quantity and quality in Delhi State, India, (Impact of Human Activity on Groundwater Dynamics, Editörler: Gehrels, H., Peters, N.E., Hoehn, E., Jensen, K., Leibundgut, C., Grif, J.). IAHS Publication no. 269, 147-153.

Vörösmarty, C.J., Green, P., Salisbury, J., Richard, B., Lammers, R.B., 2000. Global water resources: vulnerability from climate change and population growth. Nature, 289, 284-288.

Yanbay, H., 1995. Curi Irmağı (Ünye-Ordu) Alüvyonlarının Hidrojeolojisi. Karadeniz Teknik Üniversitesi, Fen Bilimleri Enstitüsü, Trabzon, Yüksek Lisans Tezi, 80 s., (yayımlanmamış).

Yavuz, H., 2004. Giresun - Trabzon - Rize İllerinin Sahil Kesimlerinin Hidrojeolojik Etüt Raporu, Devlet Su İşleri 22. Bölge Müdürlüğü, Jeoteknik Hizmetler ve Yeraltısuları Şube Müdürlüğü, Trabzon, (yayımlanmamış).

Yücel, C., 2013. Trabzon-Giresun arasındaki Tersiyer volkanitlerinin petrografisi, ${ }^{40} \mathrm{Ar}-{ }^{39} \mathrm{Ar}$ jeokronolojisi, petrokimyası, Sr-Nd-Pb izotop jeokimyası ve petrolojisi. Karadeniz Teknik Üniversitesi, Fen Bilimleri Enstitüsü, Trabzon, Doktora Tezi, 406 s, (yayımlanmamış).

Yüksek, T., 2004. Türkiye'nin Su Kaynakları ve Havza Planlamasina Dönük Genel Değerlendirmeler. Kafkas Üniversitesi, Artvin Orman Fakültesi Dergisi (1-2), 71-83. 